\title{
Carotid Artery Stenting Using a Novel Self-Expanding Braided Nickel-Titanium Stent: Feasibility and Safety Porcine Trial
}

\author{
Frank Ahlhelm • Ralf Kaufmann · Dirk Ahlhelm • \\ Mai Fang Ong · Christian Roth $\cdot$ Wolfgang Reith
}

Received: 27 November 2008/ Accepted: 16 March 2009/Published online: 16 June 2009

(C) The Author(s) 2009. This article is published with open access at Springerlink.com

\begin{abstract}
We studied the deliverability and safety of a braided, self-expanding, closed-cell nickel-titanium (NiTi) stent (E-volution, Jotec GmbH, Hechingen, Germany) especially designed for the endovascular treatment of carotid artery bifurcation stenosis with special regard to instent stenosis and thrombosis compared with a laser-cut reference nitinol stent in a porcine model of percutaneous vascular interventions. We aimed to assess histopathologic response in minipig carotid and subclavian arteries. Eight minipigs received a total of 42 stents: 14 reference stents and 28 E-volution stents. Eleven of the E-volution stents were additionally coated with heparin. Control angiography was obtained immediately before and after vascular intervention as well as 4 weeks after the procedure. Primary endpoints were 28 days of angiographic analyses as well as histomorphometric analysis, including injury score, inflammation score, luminal diameter, vessel
\end{abstract}

F. Ahlhelm $(\bowtie) \cdot$ R. Kaufmann · C. Roth · W. Reith

Clinic for Diagnostic and Interventional Neuroradiology,

School of Medicine, Saarland-University, 66421 Homburg,

Germany

e-mail: frah1@gmx.de

R. Kaufmann

e-mail: ralf.kaufmann@vascomed.de

C. Roth

e-mail: christian.roth@gmx.com

W. Reith

e-mail: nrreith@uniklinik-saarland.de

D. Ahlhelm · M. F. Ong

School of Medicine, Saarland-University,

66421 Homburg, Germany

D. Ahlhelm

e-mail: ahlhelmd@gmx.de diameter, maximal neointimal thickness, and area of instent stenosis. Secondary end points were procedural success, 28-day mortality, and stent thrombosis. All stents could be delivered successfully without procedural complications, morbidity, or mortality during our observation time. As confirmed by histology, no in-stent thrombosis was observed. Compared with common carotid arteries, subclavian arteries are significantly more vulnerable to developing in-stent stenosis caused by neointima proliferation $(p<0.05)$. Compared with the use of 1 single stent/ artery, serial application of two stents leads to a more excessive but not significantly different neointimal proliferation $(p>0.05)$. The E-volution stent, especially when heparin coated, is in line with the comparison to the lasercut reference stent displaying similar results of angiographic, histologic, and histomorphometric analyses $(p>0.05)$. Compared with the reference laser-cut stent, the self-expanding nitinol stent (E-volution) with its advanced braiding technology is feasible and safe. In our opinion, the high radial resistive force and the advanced braided design with tight stent-strut interstices may be beneficial in terms of plaque stabilization. Further studies are necessary and warranted.

Keywords Interventional radiology · Animal study · Stenting

\section{Introduction}

Carotid artery stenosis is a major cause of recurrent ischemic stroke in patients with a history of recent transient ischemic attacks or recent cerebral infarction. During the past decade, the use of endoluminal self-expanding 
metallic stents has become common practice during percutaneous carotid intervention, especially after clinical trials showed evidence of decreased restenosis rates compared with balloon angioplasty alone [1, 2]. In case of symptomatic carotid artery stenosis, carotid artery stenting (CAS) has shown its efficacy, especially in patients with high-risk factors for surgery, such as anatomically inaccessible lesions above the second cervical vertebra. Contralateral occlusion of the internal carotid artery, restenosis of previously operated bifurcation stenosis, radiationinduced stenosis, recent myocardial infarction, and endovascular treatment actually may be better treated by CAS than by surgery [3-5].

Appropriate drug therapy with dual antiplatelet medication has already shown its impact in preventing thrombosis and early in-stent stenosis, which is of major concern in terms of stent-related complications [6]. Another complication is periprocedural embolization caused by mechanical plaque destabilization during stent deployment. Recent studies indicate the importance of the stent design, suggesting that complication rates vary according to the stent type, free cell area, and cell design. With only two reports available, the level of evidence seems to be not very high; however, the possibility that the complication rate may be influenced by the stent design is an interesting theory $[7,8]$. Further investigations comparing stent devices may be warranted to analyze the impact of the stent design. Technical innovations, especially regarding stent design, may contribute to improve overall outcome in patients after CAS. Because preclinical testing is essential to investigate in vivo biocompatibility, inflammatory response, and vessel injury related to a new device, the purpose of our study was also to investigate the influence of stent design on neointimal formation and thereby instent stenosis. As a result, we conducted an experimental study to compare neointimal formation and vascular patency after implantation of the advanced braiding NiTi stent and a laser-cut NiTi stent in a porcine model (Fig. 1).

\section{Materials}

All experiments were conducted in accordance with the guidelines for animal experiments set forth by the Animal Protection Committee of the local government. With the subject under general anesthesia and using the open femoral approach, 8 minipigs received a total of 42 stents. These comprised 14 laser-cut NiTi stents (Precise RX, Cordis, Miami, FL, USA) and 28 advanced braided NiTi stents (E-volution, Jotec GmbH, Hechingen, Germany) in the carotid and subclavian arteries bilaterally. To decrease the number of the animals required for experimentation, 10 common carotid arteries were treated with 2 serial stents/

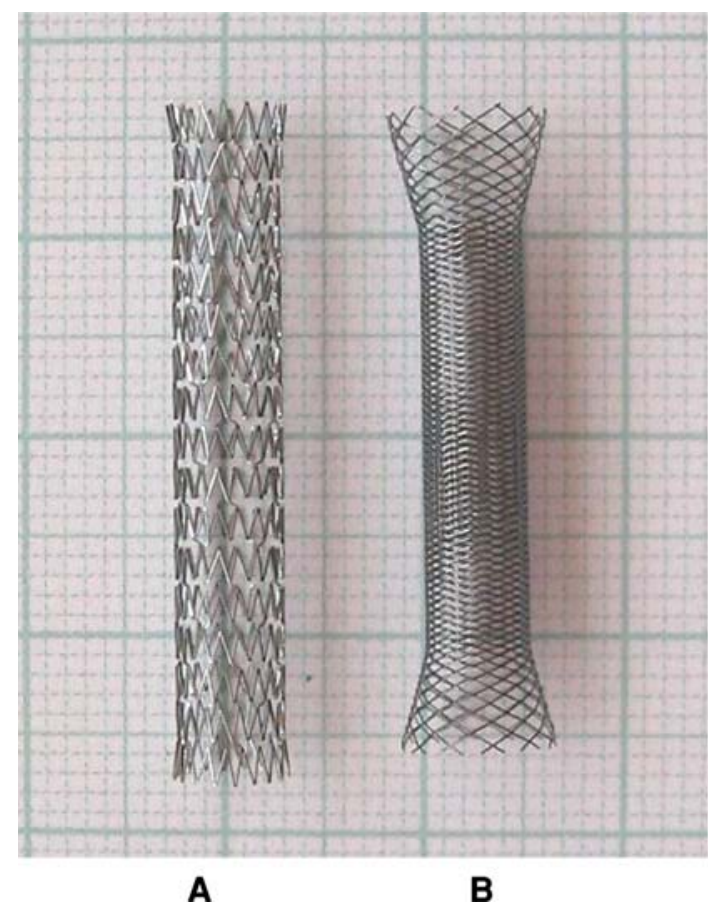

Fig. 1 A Reference testing stent with laser-cut technology (Precise RX, Cordis, Miami, FL, USA). B Testing device E-volution carotid stent with advanced braiding technology (E-volution, Jotec GmbH, Hechingen, Germany)

vessel, and 6 common carotid arteries received 1 single stent (laser-cut or braided stent)/artery. Altogether, 9 lasercut stents, 8 braided stents without heparin coating, and 9 braided stents with additional heparin coating were implanted in 16 common carotid arteries.

Two of 11 braided stents implanted in subclavian arteries were also heparin coated. Five laser-cut nitinol stents were implanted in subclavian arteries as reference. Figures $2 \mathrm{~A}$ and $\mathrm{B}$ provide examples of animal anatomy of common carotid and subclavian arteries. Angiography was obtained immediately before and after vascular intervention as well as 4 weeks after stenting immediately before killing the minipigs with a lethal dose of sodium pentobarbital.

\section{Stent Systems}

All stents were deliverable by $6 \mathrm{~F}$ deployment systems, which provide monorail technology. The deployment systems must be brought forth to target vessel position by way of $6 \mathrm{~F}$ shuttle select sheaths (Cook Medical, Bloomington, IN) and 0.014-inch guidewires. According to minipig vasculature, luminal diameter ranged from 4 to $6 \mathrm{~mm}$ (Table 1). Vessel diameter was calculated by rule of proportion using an intravascular reference (catheter tip with known size), thus avoiding errors caused by plane of projection. The stent diameters chosen were approximately $10 \%$ to $15 \%$ larger than the lumen of the target artery 
Fig. 2 Vascular anatomy of minipigs. In 7 of 8 minipigs treated, both CCAs derived from a common trunk. A Carotid bifurcation (arrow) is immediately below the skull base. B Fluoroscopic angiography 4 weeks after stenting of the left subclavian artery. C Flexibility of new braided stent
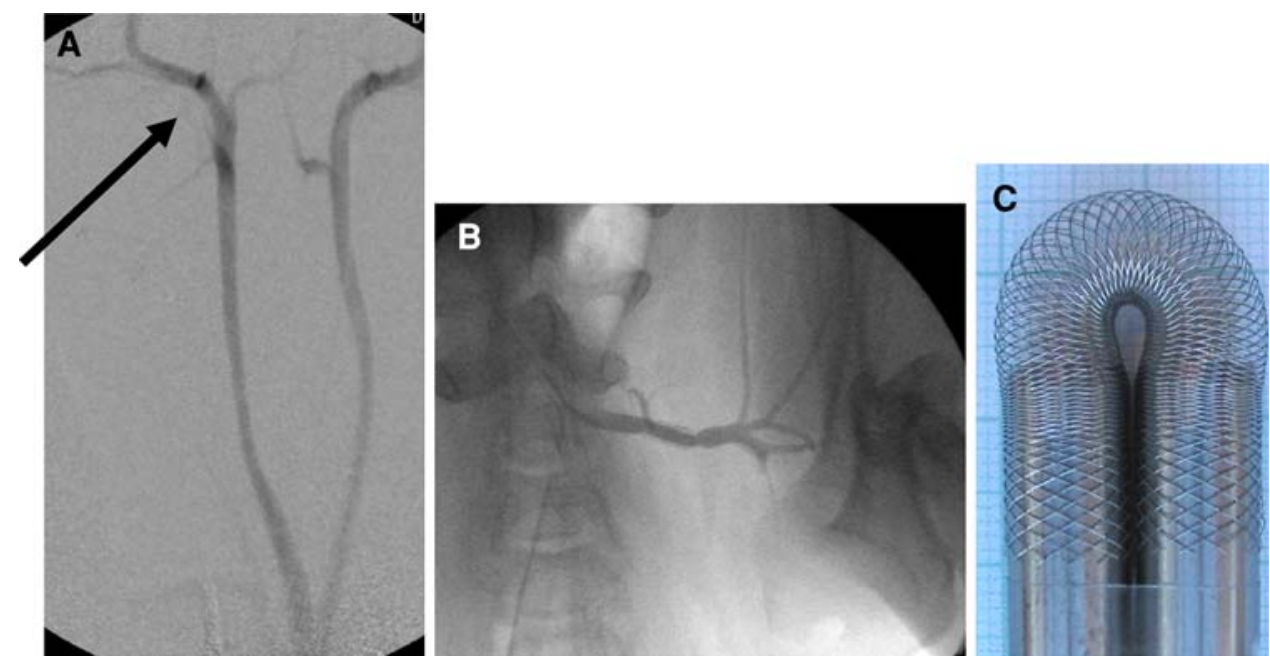

Table 1 General characteristic features of the tested stents

\begin{tabular}{|c|c|c|}
\hline Feature & $\begin{array}{l}\text { E-volution carotid stent (Jotec } \mathrm{GmbH}) \\
6 \mathrm{~F} \text { introducing sheath }\end{array}$ & $\begin{array}{l}\text { Precise RX stent (Cordis); } \\
6 \text { F introducing sheath }\end{array}$ \\
\hline \multicolumn{3}{|l|}{ Implantation $^{\mathrm{a}}$} \\
\hline Two serial stents (CCA) 1 stent (CCA) & $\begin{array}{l}7 \times 2 \text { stents (heparin coated } n=7 \text { ) } \\
3 \times 1 \text { stent (heparin coated } n=2 \text { ) }\end{array}$ & $\begin{array}{l}3 \times 2 \text { stents/vessel } \\
3 \times 1 \text { stent }\end{array}$ \\
\hline 1 stent (subclavian artery) & $11 \times 1$ stent (heparin coated $n=2$ ) & $5 \times 1$ stent \\
\hline Material & NiTi alloy $(50.6 \% \mathrm{Ni}, 49.2 \% \mathrm{Ti}$, and $0.24 \% \mathrm{Cr}$ ) & Nitinol (51.5\% $\mathrm{Ni}$ and $48.5 \% \mathrm{Ti})$ \\
\hline Design & $\begin{array}{l}\text { Braiding of } 24 \times 0.1 \mathrm{~mm} \text { wires } \\
\text { Closed cell; flared ends }\end{array}$ & $\begin{array}{l}\text { Laser-cut tubes; } 0.1 \mathrm{~mm} \text { wall thickness } \\
\text { Open cell; cell size } 5.89 \mathrm{~mm}^{2} \text {; flared ends }\end{array}$ \\
\hline Surface & Mechanically polished & Electrolytically polished \\
\hline Constrained lengths (mm) & 65 to 106 (depending on braiding angle) & 31.5 \\
\hline Unconstrained lengths (mm) & 30 & 30 \\
\hline Unconstrained diameters (mm) & 4,5 , and 6 & 5 and 6 \\
\hline Coating & $\begin{array}{l}\text { None (heparin coating } n=11) \text { : CCA }(n=9) \\
\quad \text { and subclavian artery }(n=2)\end{array}$ & None \\
\hline
\end{tabular}

${ }^{\mathrm{a}} n=42$ stents

position. All stents were $30 \mathrm{~mm}$ in their nominal implanted length. Table 1 lists the features of the tested stents.

An outstanding characteristic of braided structures is the constant luminal orifice even when bent tightly back. The flexibility to tortuous vessels (Fig. 2C) is a further attribute of the new stent. However, the vessel wall conformability of some laser-cut stents is superior to classically braided stents [9]. The invention of a new deployment system with an integrated push-pull cinematic permits the precise positioning and deployment of progressively braided stents, such as the E-volution stent. This stent adapts perfectly to the typical anatomy of the carotid bifurcation with its voluminous wide-meshed proximal part, which supports the stent in the common carotid artery. It adapts with its tightly braided distal section to the stenosis, which is typically located nearby the internal carotid artery bifurcation [10]. The test device (Fig. 1B) represents over its whole length of $30 \mathrm{~mm}$ the functional section of the basic construction. Because the new stent has high vessel-surface coverage, the arrangement of the wires may work as an extraordinary tight mesh that stabilizes the plaque, thereby preventing embolic complications. The relative stent-free surface areas versus diameter expansion of laser-cut stents (thin curve) and advanced braiding stents (thick curve) are shown in Figure 3. The curves were calculated with parameters that could be obtained through microscopic planimetric measurements. For the Precise stent (Fig. 1A) the absolute surface contact is always constant $\left(A=63.6 \mathrm{~mm}^{2}\right)$. However, the relative surface contact decreases if the stent diameter is expanded. As a result, the stent-free area increases also with an increasing stent diameter. The relative stent-free surface area of a braided stent (Fig. 1B) first increases until a local maximum has been achieved depending on diameter and initial braiding 


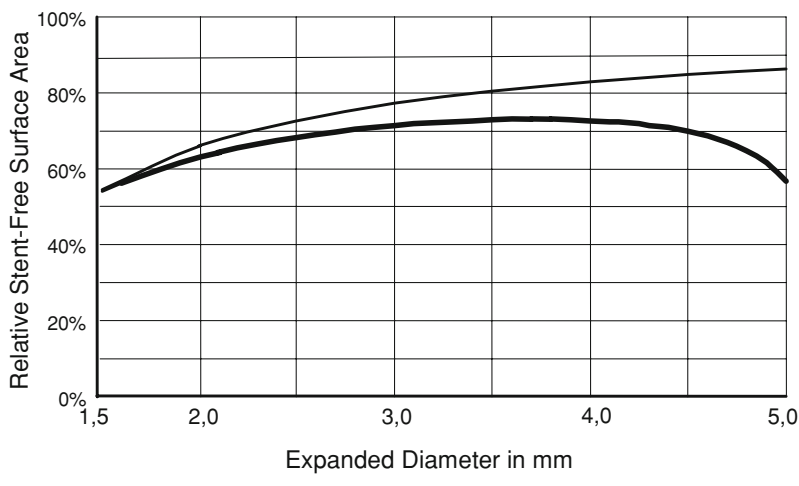

Fig. 3 Relative stent-free surface area versus diameter expansion of laser-cut stents (thin curve) and advanced braiding stents (thick curve)

angle, which can be expressed analytically. The absolute and relative and stent-free area decreases if the braided stent further expands (Table 1). The relative stent-free surface can be calculated according to the following formulas for two stents:

1. Precise stent $(30 \times 5 \mathrm{~mm}): \mathrm{A}=$ superficies surface of stent: $A=\pi \times \mathrm{D} \times \mathrm{L}$, Where $\mathrm{D}$ is diameter, $\mathrm{L}$ is length, and A (stent) $=63.6 \mathrm{~mm}^{2}$. This is a constant value of the Precise $30 \times 5-\mathrm{mm}$ stent. It was calculated by planimetric analysis, and calculation was done by means of a measuring microscope. It is a prerequisite for using the above-mentioned formula.

2. E-volution stent $(30 \times 5 \mathrm{~mm}): \mathrm{A}$ (stent free $) / \mathrm{A}=(1-$ $12 \times \delta /(\pi \times \mathrm{D} \times \sin \alpha))^{2}$.

For a given diameter $\mathrm{D}$ you can calculate the braiding angle $\alpha$ with the second formula:

$\alpha=\arccos \left(D \times \cos \alpha_{0} / D_{0}\right)$.

Parameters for the E-volution stent are as follows:

$D_{0}=5 \mathrm{~mm}, \alpha_{0}=18^{\circ}$.

This means if

$$
\begin{aligned}
\mathrm{D} & =\mathrm{D}_{0} \text { then } \\
\alpha & =\alpha_{0} \text { and } \\
\delta & =0.1 \mathrm{~mm}
\end{aligned}
$$

The radial resistive force (RRF) can be obtained by direct measurement caused by compression of a stent between two flat plates. The force curves represent the stability of a stent against a potential radial force from outside. The curves shown in Figure 4 were obtained from a tightly braided NiTi and a laser-cut NiTi stent with same relaxed diameters, lengths, and wall thicknesses. Figure 4 provides a qualitative impression of the potential of braiding concerning RRF. Typical radial compression hysteresis curves of RRF from laser-cut stents (lower curve) and from advanced braided stents (upper curve) are depicted in Figure 4.

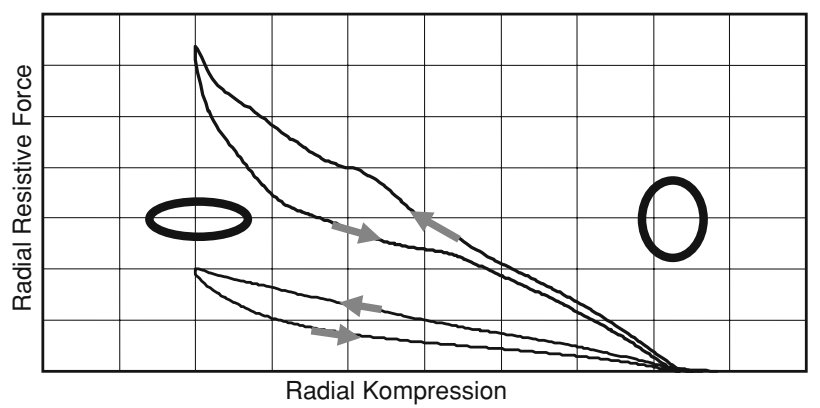

Fig. 4 Typical hysteresis curves of RRF of laser-cut stents (lower curve) and advanced braiding stents (upper curve). The stents are of equal diameter, length, and of equal wall or wire thickness

Preparation and Histomorphometry

Aspirin $(100 \mathrm{mg} / \mathrm{d})$ and $75 \mathrm{mg}$ clopidogrel were orally administered starting 3 days before the procedure and continuing until the minipigs were killed. After 28 days, angiography was repeated. Immediately thereafter, the animals were killed, the subclavian and carotid arteries rapidly removed en bloc, the vessel system flushed with $0.9 \%$ saline, and the arteries fixed by means of perfusion with $4 \%$ buffered formalin under physiologic pressure and overnight immersion. The target segments were then dissected, and samples were obtained for blinded histologic evaluation. Stent-implanted arteries were immersed in methylene methacrylate (Technovit 9100; Kulzer, Germany). For all segments with stents, three trans-sectional slices were prepared from the blocks with a coping saw, polished, and glued on acrylic plastic slides for histomorphologic evaluation, with one at the entrance of the stent, one in the middle of the stent, and one at the end of the stent. Final specimens were stained using elastica van Gieson and hematoxylin-eosin technique. After digitalizing, histomorphometric measurements were taken using the National Institute of Health image program (Scion Image; Scion, Frederick, MD). The parameters evaluated were luminal diameter, external elastic lamina diameter (vessel diameter), maximal neointimal thickness, external elastic lamina area (vessel area), luminal area, neointimal area, and area stenosis, which was determined as area stenosis $=100-([$ lumen area $\cdot 100] /$ vessel area $)$. An injury score was assigned as previously described by Schwartz et al. [11], and an inflammation score was determined according to Kornowski et al. [12] by a reader with 5 years of experience.

\section{Statistical Analysis}

Statistical difference between stent types, difference between artery types, and influence of one versus two serial stents were evaluated using nonparametric Kruskal-Wallis 
test, which is a one-way analysis of variance by ranks. The limit of statistical significance was set at $p<0.05$; however, all $p$ values should be interpreted in an explorative fashion. SPSS software used for the evaluation (version 16.0; SPSS, Chicago, IL).

\section{Results}

Stent implantation was achieved without complication. Angiography performed immediately after deployment confirmed full patency of all stents. After 28 days, all vessels treated were angiographically patent as confirmed by histologic analysis. Microscopically, the stents appeared to have been appropriately deployed, being closely opposed to the media but not penetrating through it. Neointima in carotid arteries was generally concentric. The periluminal neointima contained multiple layers of circumferentially oriented smooth muscle-like cells surrounded by extracellular collagenous matrix without neovascularization. The outer vessel diameter varied between 3 and $6.4 \mathrm{~mm}$ $(5 \pm 0.07)$. Independent from stent design, neointimal thickness of stents implanted in the subclavian arteries was generally more distinctive than in carotid arteries. Regarding the relative degree of in-stent stenosis, Figure 5 illustrates the significant difference $(p<0.05)$ between common carotid and subclavian arteries and later showed a higher rate of in-stent stenosis. Regarding inflammation and injury scores, there were no significant differences between the different stent types. In carotid arteries, braided NiTi stents showed a mean injury score of $0.7 \pm 0.6$ and an inflammation score of $1.7 \pm 0.9$, which was comparable with findings (injury score $0.3 \pm 0.2$; inflammation score: $1.9 \pm 0.8$ ) in slotted tube stents (Table 2). Mean neointimal thickness of braided stents $(0.51 \pm 0.07 \mathrm{~mm})$ was slightly higher but not significantly different compared with lasercut stents $(0.47 \pm 0.2 \mathrm{~mm})$. Histomorphometric analysis of the carotid arteries is listed in Table 2. Braided NiTi stents have been shown to develop a thicker neointima; however, no thrombosis or $>60 \%$ in-stent-stenosis was observed. As Figure 6 shows, the relative degree of in-stent stenosis in carotid arteries did not show significant differences $(p>0.05)$ between braided stents and slotted-tube NiTi stents. Heparin coating of the braided stents yielded favorable results by decreasing in-stent stenosis; however, this was statistically not significant (Fig. 6). Carotid arteries treated with only one stent showed lower in-stent stenosis compared with the condition of two serial stents used per treated artery (Fig. 7). However, this difference was not statistically significant $(p>0.05)$ (Fig. 8).

\section{Discussion}

CAS is a rapidly evolving technique that has shown to be technically feasible with an acceptable rate of complications [13-17]. Recently published guidelines from interdisciplinary consensus groups were defined as demanding, among others things, dedicated training of the interventionalist, technical success rates $>90 \%$, and major complication rates $<5 \%$ in symptomatic and $<7.5 \%$ in asymptomatic patients with high risk for surgery [18-20]. In addition to guidelines to ascertain high-quality performance of the procedure, advances in stent technology, especially stent design, may contribute to decrease periprocedural complications.

The closed cell stent design covers a greater percentage of the vascular wall in the stented region and thereby has less uncovered cell area, which offers greater potential to scaffold. This may support fractured plaque and stabilize
Fig. 5 Examples of transverse histologic slices through arteries treated with stents. A

Hematoxylin-eosin stain. B Masson Goldner stain (original magnification $\times 20$ ). Neointima formation within the subclavian arteries A was significantly more excessive $(p<0.05)$ than in common carotid arteries (B). In the latter, stenosis was typically concentric, whereas more eccentric stenoses could be observed in subclavian arteries

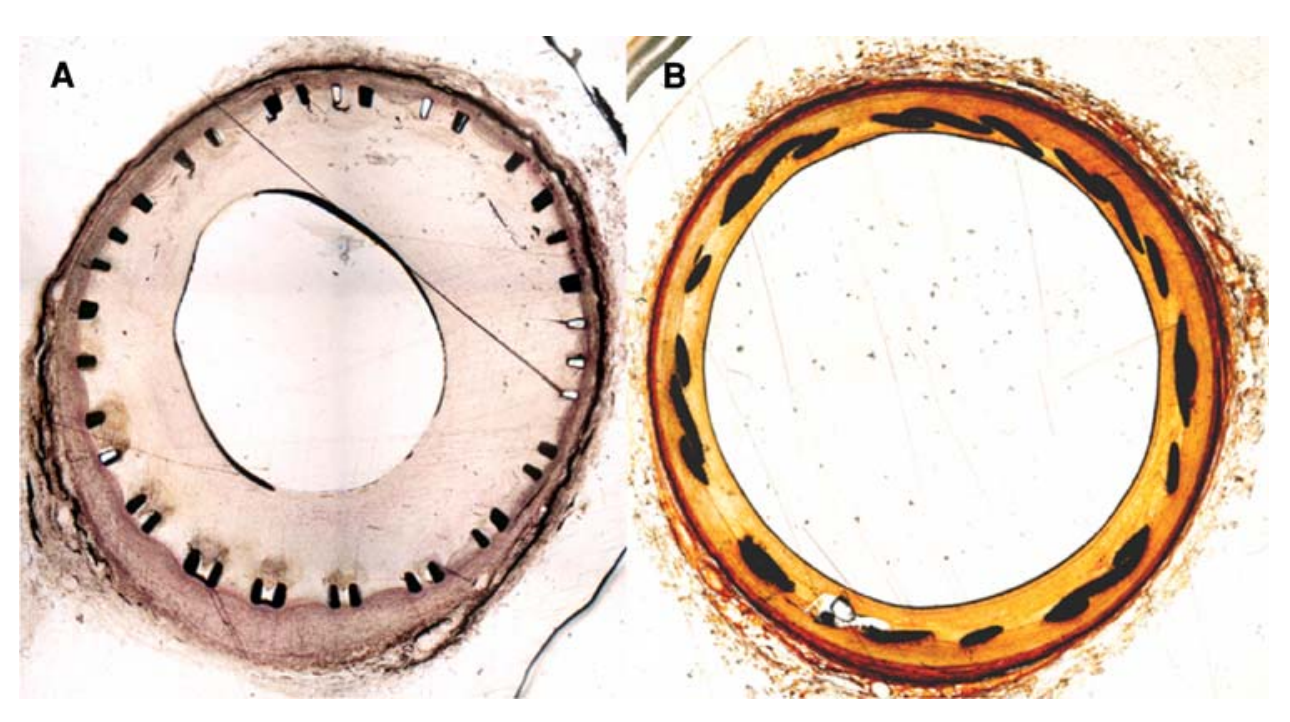


Table 2 Histomorphometric findings in the carotid arteries ${ }^{\mathrm{a}}$

\begin{tabular}{|c|c|c|c|c|c|c|c|c|}
\hline No. & $\begin{array}{l}\text { Descriptive } \\
\text { parameters }\end{array}$ & $\begin{array}{l}\text { Vessel } \\
\text { diameter } \\
(\mathrm{mm})\end{array}$ & $\begin{array}{l}\text { Luminal } \\
\text { diameter } \\
(\mathrm{mm})\end{array}$ & $\begin{array}{l}\text { Maximum } \\
\text { neointimal } \\
\text { thickness } \\
(\mathrm{mm})\end{array}$ & $\begin{array}{l}\text { Neointimal } \\
\text { area }\left(\mathrm{mm}^{2}\right)\end{array}$ & $\begin{array}{l}\text { Stenosis } \\
(\%)\end{array}$ & $\begin{array}{l}\text { Injury score } \\
\text { points (0 to } 3)\end{array}$ & $\begin{array}{l}\text { Inflammation } \\
\text { score points } \\
(0 \text { to } 3)\end{array}$ \\
\hline \multirow{3}{*}{$\begin{array}{l}\text { Precise stent } \\
\quad(n=9)\end{array}$} & Mean \pm SD & $5.5 \pm 0.5$ & $4.4 \pm 0.4$ & $0.5 \pm 0.2$ & $8.3 \pm 2.1$ & $34 \pm 6.9$ & $0.36 \pm 0.2$ & $1.7 \pm 0.6$ \\
\hline & Maximum & 6.4 & 5.2 & 0.8 & 6.0 & 49 & 1 & 3 \\
\hline & Minimum & 5.1 & 4.0 & 0.2 & 1.2 & 27 & 0 & 1.1 \\
\hline \multirow{3}{*}{$\begin{array}{l}\text { E-volution } \\
\quad \text { stent } \\
\quad(n=8)\end{array}$} & Mean SD & $4.4 \pm 0.9$ & $3.4 \pm 0.9$ & $0.5 \pm 0.1$ & $6.3 \pm 1.4$ & $40.1 \pm 10.2$ & $0.7 \pm 0.7$ & $1.6 \pm 0.9$ \\
\hline & Maximum & 5.1 & 4.3 & 0.5 & 8.4 & 56.1 & 2 & 3 \\
\hline & Minimum & 3.0 & 2.0 & 0.47 & 4.1 & 29.4 & 0 & 0.7 \\
\hline \multirow{3}{*}{$\begin{array}{l}\text { E-volution-Hep } \\
\quad \text { stent } \\
\quad(n=9)\end{array}$} & Mean \pm SD & $4.7 \pm 0.5$ & $3.8 \pm 0.5$ & $0.5 \pm 0.1$ & $6.3 \pm 1.1$ & $35 \pm 7.6$ & $0.7 \pm 0.6$ & $1.8 \pm 0.9$ \\
\hline & Maximum & 5.6 & 4.7 & 0.6 & 7.6 & 52.3 & 2 & 3 \\
\hline & Minimum & 4.2 & 3.1 & 0.4 & 4.9 & 28.8 & 0 & 0.6 \\
\hline
\end{tabular}

${ }^{a}$ Number of carotid stents results related to serial stentings (2 stents/vessel), which was performed in five of the eight animals. Statistical analysis using nonparametric Kruskal-Wallis test, which is a one-way analysis of variance by ranks, showed no significant difference $(p<0.05)$

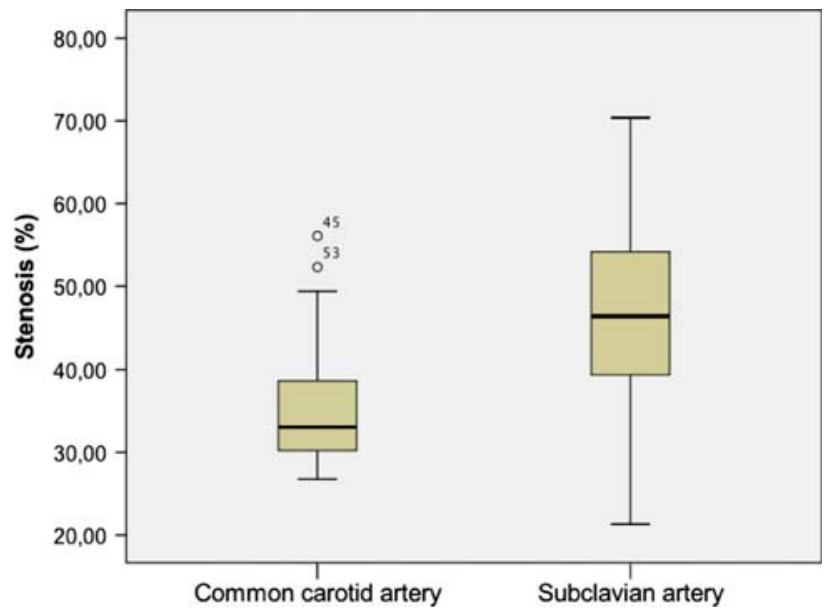

Fig. 6 Relative degree of stenosis. Subclavian arteries showed significant $(p<0.05)$ higher degree of in-stent stenoses compared with carotid arteries

material that could embolize to the brain. A recent study regarding the use of a similarly tightly braided stent (without additional coil embolization) for treatment of aneurysms has shown its efficacy to decrease intra-aneurysmal perfusion [22]. Based on a retrospective analysis, Bosiers et al. suggested that a smaller free-cell area associated with closed-cell stents may prevent plaque embolization and therefore may decrease periprocedural and postprocedural ischemic events [10]. Nevertheless, this hypothesis has not yet been confirmed by other randomized trials [5]. A retrospective analysis of $>700$ carotid stenting procedures showed only a trend (without statistic significance) toward lower event rates with closed-cell stents [21]. Although clinical outcome after CAS is not influenced by only a single variable, the influence of stent design that avoids, or at least decreases, risk of

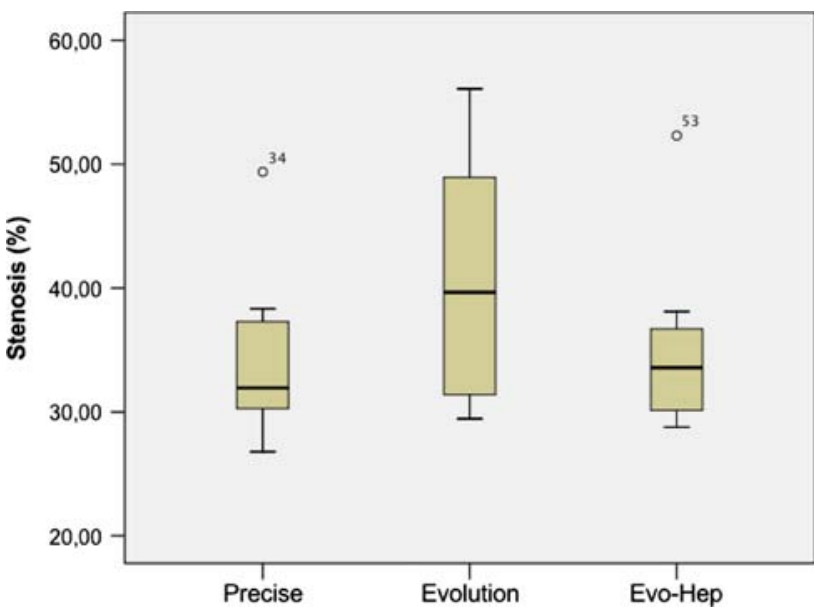

Fig. 7 Influence of stent design (Precise $[n=9]$, E-volution $[n=8]$, E-volution $[n=9])$. Heparin coating (E-volution-Hep stent) led to decreased neointima formation of braided stents. However, there was no statistically significant difference between these three groups $(p>0.05)$

periprocedural complications is not fully understood. Because several animal studies exist regarding the use of the Precise stent, we focused on the novel stent design, which explains the higher number of vessels treated using the novel stent $[23,24]$. As Verheye observed in minipigs, maximal intimal thickness in closed-cell laser-cut NiTi stents depends on the anatomic vessel to be stented having a mean diameter of $0.65 \pm 0.13 \mathrm{~mm}$ described in the iliac arteries and $0.55 \pm 0.07 \mathrm{~mm}$ in the carotid arteries. In our animal cohort, neointimal thickness within carotid and subclavian arteries stented with the same type of United States Food and Drug Administration-approved NiTi stents was also different, suggesting that subclavian arteries are more susceptible to developing in-stent stenosis. This has 




Fig. 8 Influence of two serial stents on in-stent stenosis caused by intimal proliferation. Compared with only 1 stent/vessel treated, two serial stents increased the danger of neointima formation. This difference was not statistically significant $(p<0.05)$

also been reported for iliac arteries in minipigs [24] and may be attributed to different physiologic strains in subclavian compared with carotid arteries. This also may explain the thicker neointima in Wallstents (Wallstent, Boston Scientific Corp., Natick, MA, USA) implanted in subclavian arteries compared with thinner neointimal proliferation in iliac arteries of sheep [23].

High-pressure inflation with consequently higher injury scores has been suggested as a cause of increased neointima formation [25]. Compared with other NiTi stents, one advantage of this new stent is a high RRF. Because of its braided design, radial forces are much higher than those of laser-cut stents, which may supersede additional balloon angioplasty to restore the stenosis after stent placement. The lack of requirement for additional balloon angioplasty may at least theoretically contribute to decrease vessel damage. In addition, progressive intrinsic stent expansion after implantation does not appear to stimulate neointimal formation-at least not in the coronary circulation-and therefore may provide a mechanical solution to decrease neointima proliferation [25]. Despite the high amount of metal in braided stents compared with laser-cut stents, the range of injury scores and neointima formation we observed was relatively low compared with other studies $[23,24]$. This might be explained by the high surface coverage of braided stents, which generates only relatively low penetrative force of each individual stent strut, thus limiting the extent of vessel wall penetration and injury.

Given the great variety of different laser-cut stent design available today, the braided Wallstent, which represents the first stent generation, seems to be a relic from the past. However, in many cases it is best indicated for CAS therapy because a huge percentage of experienced interventionalists use it, and its special features and mechanical advantages, as compared with laser-cut stents, lend to its widespread use. However, the Wallstent concept does not exploit the full range of braiding options. Perhaps this is related to conventional deployment techniques, which demand no or faint foreshortening stent constructions. The invention of a new deployment system with an integrated push-pull cinematic permits the precise positioning and deployment of progressively braided stents, such as the Evolution stent.

In the case of placement of 2 serial stents/treated vessel, which can be necessary because of stent malposition and which is considered to be a risk factor for in-stent stenosis [26], neointima thickness was slightly greater than in the case of a single stent, which was observed not only for slotted tubes but also for braided NiTi stents. In two carotid arteries, an overlapping of strut elements was observed; however, this did not produce in-stent thrombosis or stent occlusion. This suggests the feasibility of the novel stent in cases of malposition and the need for a second stent for technical success. Compared with bare metal stents without coating, heparin coating has been shown to be beneficial in decreasing neointimal formation and subsequent in-stent restenosis, which has been reported previously for coronary arteries [27, 28] and also for carotid arteries [28, 29].

This study has several limitations. Differences in the structure and physiologic characteristics of carotid arteries in minipigs compared with those in patients with atherosclerosis may have had an unpredictable influence. This might also explain differences between the reaction of the vessel wall in carotid compared with subclavian arteries. There is no animal model of human carotid disease; there are only animal models of how devices will behave in wellcharacterized animal models [30-32]. True efficacy and safety can only be proven in humans. However, the minipig model is considered to be a suitable model for preclinical testing of the in-stent stenosis [24, 33].

Another limitation results from the short observation period of only 4 weeks. This covers the most critical time with respect to thrombotic events and healing. However, it remains to be determined how observations will be made in animals and especially in human patients. In addition, it must be pointed out that regardless of the animal model used, the transfer of results to humans is generally limited but must be undertaken before its application in humans [34].

\section{Conclusion}

Compared with the reference laser-cut stent, the novel braided nitinol stent device for treatment of carotid artery stenosis has two innovative characteristics: a three-fold greater RRF as well as a high surface coverage. The self- 
expanding nitinol stent (E-volution), with its advanced braiding technology, is feasible and safe. However, because preclinical studies are necessary to assure the safety of the device, especially concerning neointima formation and in-stent stenosis, animal studies must precede its application for human carotid stenosis.

Acknowledgments We express gratitude to M. D. Menger (head of the Clinic for Experimental Surgery, Saarland University, School of Medicine) and his team for assistance.

Open Access This article is distributed under the terms of the Creative Commons Attribution Noncommercial License which permits any noncommercial use, distribution, and reproduction in any medium, provided the original author(s) and source are credited.

\section{References}

1. Theron JG, Payell GG, Coskun O, Huet HF, Guimaraens L (1996) Carotid artery stenosis: treatment with protected balloon angioplasty and stent placement. Radiology 201:627-636

2. Wholey MH, Wholey M, Bergeron P, Diethrich EB, Henry M, Laborde JC et al (1998) Current global status of carotid artery stent placement. Cathet Cardiovasc Diagn 44:1-6

3. Yadav J, for the SAPPHIRE Investigators (2002) Stenting and Angioplasty with Protection in Patients at High Risk for Endarterectomy: The SAPPHIRE study. Circulation 106:2986-2989

4. Yadav JS, Wholey MH, Kuntz RE et al (2004) Protected carotidartery stenting versus endarterectomy in high-risk patients. $\mathrm{N}$ Engl J Med 351:1493-1501

5. Gurm HS, Yadav JS, Fayad P, Katzen BT, Mishkel GJ, Bajwa TK et al (2008) Long-term results of carotid stenting versus endarterectomy in high-risk patients. N Engl J Med 358:1572-1579

6. Jiang WJ, Du B, Leung TW, Xu XT, Jin M, Dong KH (2007) Symptomatic intracranial stenosis: cerebrovascular complications from elective stent placement. Radiology 243:188-197

7. Hart JP, Peeters P, Verbist J, Deloose K, Bosiers M (2006) Do device characteristics impact outcome in carotid artery stenting? J Vasc Surg 44:725-731

8. Bosiers M, de Donato G, Deloose K, Verbist J, Peeters P, Castriota F et al (2007) Does free cell area influence the outcome in carotid artery stenting? Eur J Vasc Endovasc Surg 33:135-1423

9. Tanaka N, Martin JB, Tokunaga K, Abe T, Uchiyama Y, Hayabuchi $\mathrm{N}$ et al (2004) Conformity of carotid stents with vascular anatomy: evaluation in carotid models. AJNR Am J Neuroradiol 25:604-607

10. Theiss W, Hermanek P, Mathias K, Ahmadi R, Heuser L, Hoffmann FJ et al (2004) Pro-CAS: a prospective registry of carotid angioplasty and stenting. Stroke 35:2134-2139

11. Schwartz RS, Huber KC, Murphy JG, Edwards WD, Camrud AR, Vlietstra RE et al (1992) Restenosis and the proportional neointimal response to coronary artery injury: results in a porcine model. J Am Coll Cardiol 19:267-274

12. Kornowski R, Hong MK, Tio FO, Bramwell O, Wu H, Leon MB (1998) In-stent restenosis contributions of inflammatory responses and arterial injury to neointimal hyperplasia. J Am Coll Cardiol 31:224-230

13. Wholey MH, Wholey M, Mathias K, Roubin GS, Diethrich EB, Henry M et al (2000) Global experience in cervical carotid artery stenting. Cathet Cardiovasc Diagn 50:160-167
14. Kovacic JC, Roy PR, Baron DW, Gunalingam B, Muller DW (2005) Percutaneous carotid artery stenting: a strategy in evolution. Intern Med J 35:143-150

15. Coward LJ, Featherstone RL, Brown MM (2005) Safety and efficacy of endovascular treatment of carotid artery stenosis compared with carotid endarterectomy: a Cochrane systematic review of the randomized evidence. Stroke 36:905-911

16. Hauth EA, Jansen C, Drescher R, Schwarz M, Christmann A, Jaeger $\mathrm{H}$ et al (2006) Angiographic follow-up after carotid artery stenting of bifurcation stenosis. Rofo 178:794-800

17. Collaborative Group SPACE, Ringleb PA, Allenberg J, Brückmann H, Eckstein HH, Fraedrich G et al (2006) Thirty-day results from the SPACE trial of stent-protected angioplasty versus carotid endarterectomy in symptomatic patients: a randomized noninferiority trial. Lancet 368(9543):1239-1247

18. Citron SJ, Wallace RC, Lewis CA, Dawson RC, Dion JE, Fox AJ et al (2003) Quality improvement guidelines for adult diagnostic neuroangiography. Cooperative study between ASITN, ASNR, and SIR. J Vasc Interv Radiol 14:257-262

19. ACCF/SCAI/SVMB/SIR/ASITN (2007) Clinical expert consensus document on carotid stenting: a report of the American College of Cardiology Foundation Task Force on Clinical Expert Consensus Documents. Am Coll Cardiol 49:126-170

20. Bates ER, Babb JD, Casey DE Jr, Cates CU, Duckwiler GR, Feldman TE et al (2007) ACCF/SCAI/SVMB/SIR/ASITN 2007 clinical expert consensus document on carotid stenting. Vasc Med 12:35-83

21. Reimers B, Nikas D. Carotid stent design: closed-cell, open-cell does not really matter. Oral presentation at 6th ICCA, Frankfurt, Germany, November 23-25, 2006

22. Ahlhelm F, Roth C, Kaufmann R, Schulte-Altedorneburg G, Romeike BF, Reith W (2007) Treatment of wide-necked intracranial aneurysms with a novel self-expanding two-zonal endovascular stent device. Neuroradiology 49:921-926

23. Schürmann K, Vorwerk D, Kulisch A, Stroehmer-Kulisch E, Biesterfeld S, Stopinski T et al (1996) Neointimal hyperplasia in low-profile Nitinol stents, Palmaz stents, and Wallstents: a comparative experimental study. Cardiovasc Intervent Radiol 19:248-254

24. Verheye S, Salame MY, Robinson KA, Post MJ Carrozza JP Jr, Baim DS et al (1999) Short- and long-term histopathologic evaluation of stenting using a self-expanding nitinol stent in pig carotid and iliac arteries. Catheter Cardiovasc Interv 48:123-316

25. Carter AJ, Scott D, Laird JR, Bailey L, Kovach JA, Hoopes TG et al (1998) Progressive vascular remodeling and reduced neointimal formation after placement of a thermoelastic self-expanding nitinol stent in an experimental model. Cathet Cardiovasc Diagn 44:193-201

26. Kastrati A, Elezi S, Dirschinger J, Hadamitzky M, Neumann FJ, Schömig A (1999) Influence of lesion length on restenosis after coronary stent placement. Am J Cardiol 83:1617-1622

27. Hårdhammar PA, van Beusekom HM, Emanuelsson HU, Hofma SH, Albertsson PA, Verdouw PD et al (1996) Reduction in thrombotic events with heparin-coated Palmaz-Schatz stents in normal porcine coronary arteries. Circulation 93:423-430

28. Matsumoto Y, Shimokawa H, Morishige K, Eto Y, Takeshita A (2002) Reduction in neointimal formation with a stent coated with multiple layers of releasable heparin in porcine coronary artery. J Cardiovasc Pharmacol 39:513-522

29. Lin PH, Chronos NA, Marijianowski MM, Chen C, Conklin B, Bush RL et al (2003) Carotid stenting using heparin-coated balloon-expandable stent reduces intimal hyperplasia in a baboon model. J Surg Res 112:84-90

30. Müller-Hülsbeck S, Gühne A, Tsokos M, Hüsler EJ, Schaffner SR, Paulsen F et al (2006) Stent-protected carotid angioplasty 
using a membrane stent: a comparative cadaver study. Cardiovasc Intervent Radiol 29:630-636

31. Müller-Hülsbeck S, Hüsler EJ, Schaffner SR, Jahnke T, Glass C, Wenke $R$ et al (2004) An in vitro analysis of a carotid artery stent with a protective porous membrane. J Vasc Interv Radiol 15:1295-1305

32. Link J, Feyerabend B, Grabener M, Linstedt U, Brossmann J, Thomsen $\mathrm{H}$ et al (1996) Dacron-covered stent-grafts for the percutaneous treatment of carotid aneurysms: effectiveness and biocompatibility experimental study in swine. Radiology 200: 397-401

33. Speck U, Scheller B, Abramjuk C, Breitwieser C, Dobberstein J, Boehm M et al (2006) Neointima inhibition: comparison of effectiveness of non-stent-based local drug delivery and a drugeluting stent in porcine coronary arteries. Radiology 240:411-418

34. Narayanaswamy M, Wright KC, Kandarpa K (2000) Animal models for atherosclerosis, restenosis, and endovascular graft research. J Vasc Interv Radiol 11:5-17 